\title{
Transoccipital endoscopic fenestration of atrial cysts causing ventricular entrapment
}

\author{
Jason A. Ellis, MD, ${ }^{1}$ Paul C. McCormick II, BA, ${ }^{1}$ Neil A. Feldstein, MD, ${ }^{1}$ and Saadi Ghatan, MD² \\ ${ }^{1}$ Department of Neurological Surgery, Columbia University Medical Center; and ${ }^{2}$ Department of Neurosurgery, Mount Sinai \\ Roosevelt Hospital, New York, New York
}

\begin{abstract}
OBJECT Cystic lesions in the atrium (trigone) of the lateral ventricle may become symptomatic due to obstruction of physiological CSF circulation and/or from mass effect on adjacent structures. A minimally invasive approach that not only allows for straightforward access to multiple regions of the atrial cyst wall, but also enables direct inspection of the entire lateral ventricular system, has not been elaborated. In this paper the authors describe their experience with the endoscopic transoccipital horn approach for treating cystic lesions in the atrium of the lateral ventricle.
\end{abstract}

METHODS A retrospective review was performed of all patients who underwent endoscopic surgical treatment for cysts in the atrium of the lateral ventricle between 1999 and 2014.

RESULTS The cohort consisted of 13 consecutive patients who presented with symptomatic lateral ventricular entrapment due to the presence of an atrial cyst. There were 9 male and 4 female patients, with a median age of 5 years. Headache was the most common complaint at presentation. The transoccipital horn approach facilitated successful cyst reduction and fenestration in all cases. Temporal and occipital horn entrapment was reversed in all cases, with reestablishment of a physiological CSF flow pattern throughout the ventricles. Hydrocephalus was also reversed in all patients presenting with this neuroimaging finding at presentation. No cyst or ventricular entrapment was noted to recur during a mean follow-up period of 36 months. No patient in the study cohort required repeat surgery or permanent CSF diversion postoperatively.

CONCLUSIONS The endoscopic transoccipital horn approach represents a safe and effective treatment strategy for patients with symptomatic atrial cysts of the lateral ventricle. Using this minimally invasive technique, all poles of the lateral ventricular system can be visualized and the unobstructed flow of CSF can be confirmed after cyst resection obviating the need for additional diversion.

http://thejns.org/doi/abs/10.3171/2014.11.PEDS14227

KEY WORDS arachnoid cyst; brain tumor; endoscope; fenestration; hydrocephalus; intraventricular; minimally invasive; technique

$\mathrm{C}$ YSTIC lesions in the atrium (trigone) of the lateral ventricle may become symptomatic due to obstrucmass effect on adjacent structures. Temporal and occipital horn entrapment is often noted in the presence of large atrial cysts. These cysts are either congenital or acquired in the setting of CNS infection, neoplasia, or trauma. Fluid diversion from the entrapped ventricular segments or from the cyst itself was often attempted in the past, but such shunts are prone to failure. ${ }^{12,16-18,28,29}$ Alternatively, microsurgical and frame-based stereotactic surgeries have also been reported in the treatment of intraventricular cysts with variable rates of success. ${ }^{1,3,7,14,17,18,20,22,25}$ More recent reports of endoscopic or endoscopically assisted surgeries have shown promising results for treating intraventricular lesions. ${ }^{2,4-6,8-10,19,21,23,26,27,30-32}$ However, these reports neither detail a specific endoscopic approach designed for treating atrial cysts nor do they focus on the longer-term outcomes after treating these lesions.

In this paper we describe our experience with the stereotactic endoscopic transoccipital horn approach for treating cystic lesions in the atrium of the lateral ventricle. This minimally invasive approach not only allows for straightforward access to multiple regions of the atrial cyst wall, but also enables direct inspection of the entire lateral ventricular system. The advantages conferred by the ability to directly confirm physiological CSF flow obviating the need for shunt placement, the utility of frameless ste- 
reotaxy for navigating distorted ventricular systems, and the clinical outcomes we achieve after treating atrial cysts are described.

\section{Methods \\ Data Collection}

We performed a retrospective review of all patients who underwent endoscopic surgical treatment for cysts in the atrium of the lateral ventricle between 1999 and 2014 at Columbia University Medical Center. The office charts, electronic medical records, and available radiological data were reviewed for each patient in accordance with the standards of the Institutional Review Board of the Columbia University Medical Center. Patient demographics, details of presentation, cyst location, operative approach, operative complications, and clinician assessment at last follow-up evaluation were recorded.

\section{Surgical Technique}

The patient is placed on the operating table in a lateral decubitus position with the cyst side up (Fig. 1). Frameless stereotaxy with optical (head immobilized) or electromagnetic (no head immobilization) referencing systems may be used. We have had success with both the Stealth AxiEM (Medtronic) and the Brainlab navigation systems. Preoperative volumetric MRI with a neuronavigation protocol is registered after the patient is positioned on the operating table and general anesthesia is induced. The patient is then prepared and draped in a usual sterile fashion.

In defining the optimal trajectory, it is critical that the patient is positioned straight lateral and that an occipital entry (Frazier) point is chosen. Confirmation of the proposed bur-hole site with navigation is always obtained. Adherence to these principles will enable the surgeon to easily access both the temporal and frontal horns through the same opening. Ideally, one should be able to fully visualize the atrium of the lateral ventricle and follow the curve of the choroid plexus around the more lateral fibers of the splenium of the corpus callosum. This trajectory minimizes operative transgression of neural tissue because it avoids the optic radiations laterally, the rolandic areas superiorly, and the visual association areas inferiorly. Navigation is helpful for confirming that a sufficiently lateral trajectory has been chosen such that the endoscope does not have to be unduly torqued to reach the areas of interest.

Once a trajectory has been chosen and the bur hole is made, a cruciate dural incision is performed and its leaflets are coagulated with bipolar cautery. Arachnoid mater above the cortical surface at the entry site is also coagulated. An introducer sheath and trocar are then placed into the occipital horn without puncturing the cyst.

A rigid, $0^{\circ}$, MINOP glass rod endoscope (Aesculap) or disposable Channel Neuroendoscope (Medtronic) is used for direct intraventricular visualization. The endoscopic tip may be tracked in real time by placing the navigation stylet through the working channel of the endoscope. The posterior cyst wall should be clearly distinguished from ependyma. Using a combination of monopolar and bipolar electrocautery, a small fenestration is created in the pos-

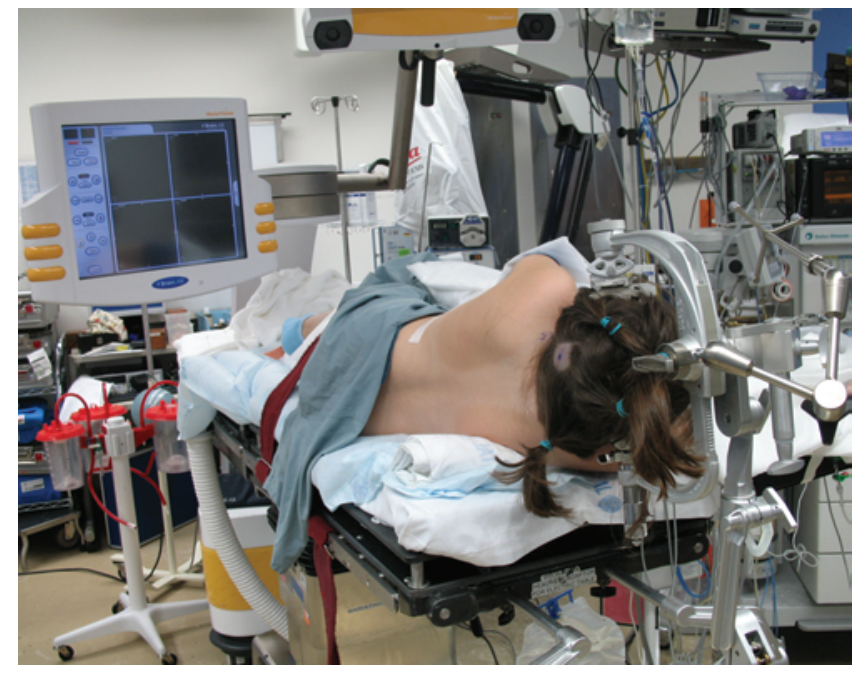

FIG. 1. Photograph showing patient positioning. The patient is positioned lateral on the operating table with the side of the encysted ventricle up for the endoscopic transoccipital approach. Accurate incision and bur-hole placement are facilitated by use of frameless stereotaxy, as depicted. Figure is available in color online only.

terior cyst wall (Fig. 2). The external surface of the cyst is then cauterized to shrink it to a small fraction of its original size (Video 1).

VIDEO 1. Clip showing transoccipital endoscopic surgery. Copyright Saadi Ghatan. Published with permission. Click here to view with Media Player. Click here to view with Quicktime.

Wide fenestration of the remaining cyst in multiple areas is then fashioned, and the wall is removed if it is not tightly adherent to neural tissue or choroid plexus. Endoscopic navigation to both the ipsilateral temporal and frontal horn poles is performed to ensure adequate decompression with free flow of CSF within the lateral ventricle. In straightforward cases without loculations, following the choroid plexus allows one to navigate in the ventricular system to ensure that entrapment has been relieved. In complex cases with loculated cysts, multiple complex membranes, and/or distorted ventricular landmarks (such as the choroid plexus, septal/thalamostriate veins, and hippocampal formation), frameless neuronavigation becomes extremely useful.

A wide septal fenestration may be performed using this approach if additional decompression is desired. At the conclusion of the procedure, the endoscope and sheath are removed followed by placement of a rolled pledget of dry gelfoam into the corticotomy site. The scalp is closed in the usual manner.

\section{Results}

The cohort consisted of 13 consecutive patients who presented with symptomatic lateral ventricular entrapment due to the presence of an atrial cyst (Fig. 3). There were 9 male and 4 female patients with median age of 5 years (range 4 months to 54 years). Headache was the most common complaint at presentation, but seizures (epilepsy), visual disturbances, hemiparesis, meningitis (postinfectious), and prenatal finding were also notable 

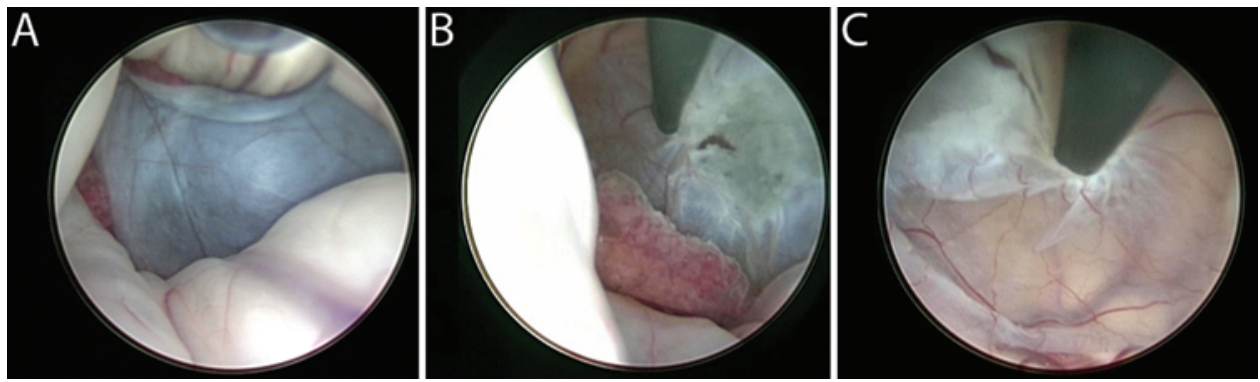

FIG. 2. Endoscopic photographs of cyst fenestration and shrinkage. The posterior atrial cyst wall is visualized after placement of the endoscope within the entrapped occipital horn of the lateral ventricle (A). A small fenestration is created in the posterior cyst wall (B) to facilitate shrinkage of the cyst with cautery (C). Figure is available in color online only.

presentations (Table 1). In the 2 infants with a prenatal diagnosis of atrial cyst, the decision to proceed with surgery was based on progressive hydrocephalus and/or skull deformity in the setting of an enlarging cyst over a $6-12$ week period.

Of note, 4 patients had behavioral or psychiatric disturbances at the time of presentation. One patient presented with bipolar disorder, 2 patients presented with attentiondeficit hyperactivity disorder (ADHD), and 1 patient presented with both conditions. We are aware of only 1 prior report of an atrial cyst presenting in a patient with psychiatric symptoms. ${ }^{21}$ It was suggested, without evidence, that the amygdala-hippocampal complex may have been dysfunctional due to direct pressure or that ventricular trapping caused a disturbance in monoamine metabolism.

The transoccipital horn approach facilitated successful cyst fenestration and reduction in all cases (Fig. 4). Temporal and occipital horn entrapment was reversed in all cases with reestablishment of a physiological CSF flow pattern throughout the ventricles. Hydrocephalus was also reversed in all patients presenting with this neuroimaging finding at presentation. No significant blood loss (5-25 $\mathrm{ml}$ ) or operative complications were noted. Hospital stays ranged from 1 to 4 postoperative days. No cyst or ventricular entrapment was noted to recur during a mean followup of 36 months (range 2-123 months) since the time of surgery. No patient in the study cohort required repeat surgery or permanent CSF diversion postoperatively. The 1 patient (Case 9) who presented with a ventriculoperitoneal shunt already in place remained shunt dependent. All patients were observed to be clinically improved compared with their preoperative status (Table 1).

\section{Discussion}

Intraventricular lesions are increasingly being treated with the use of endoscopic surgical techniques. ${ }^{2,4-6,8-10 \text {, }}$ 19,21,23,26,27,30-32 Cystic lesions within the atrium of the lateral ventricle present a unique challenge due to their location at the confluence of the frontal, temporal, and occipital horns. Thus, any surgical plan for their management requires a technique capable of eliminating membranes at the orifices of these 3 ventricular horns and ideally enables direct visualization of the entire ventricular system. The endoscopic transoccipital horn approach we describe is a single, minimally invasive approach that accomplishes all these goals.

Our results indicate that the endoscopic transoccipital horn approach is a safe and effective way to reduce, fenestrate, and/or excise atrial cysts. The surgical objective of reestablishing physiological CSF flow throughout the lateral ventricles was realized in all patients within our cohort. We encountered no cyst recurrence or surgical complications during the course of this study and all patients experienced symptomatic improvement postoperatively.

In cases of atrial cysts in children with behavioral disorders, we could not determine definitively whether the cyst was causative of behavioral symptoms. However, in-
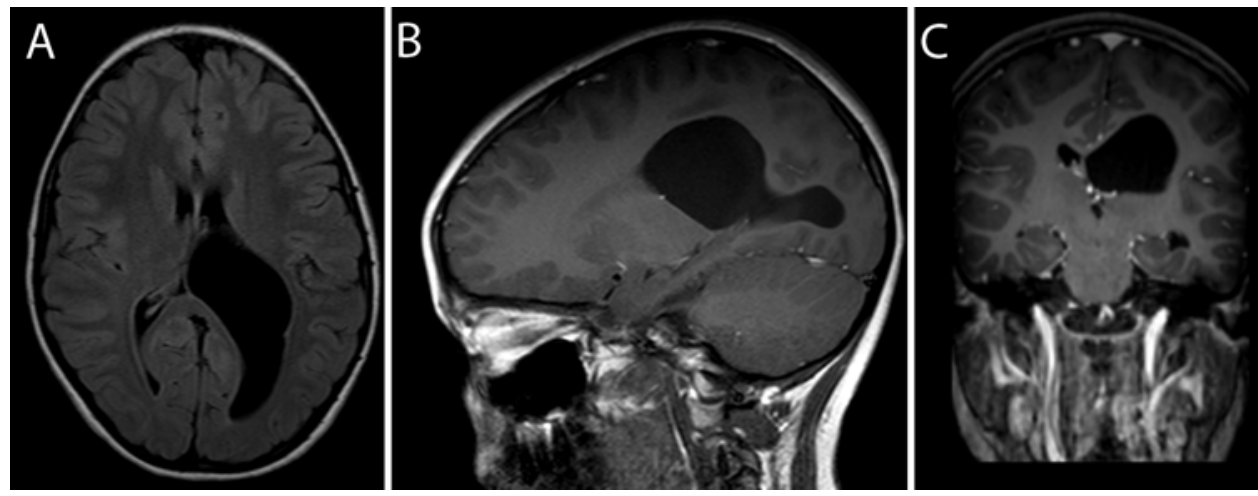

FIG. 3. The typical appearance of an atrial arachnoid cyst is demonstrated on axial (A), sagittal (B), and coronal (C) MR images. Left occipital ( $A$ and $B$ ) and temporal horn $(C)$ dilation due to entrapment by the cyst is evident. 
TABLE 1. Patient characteristics

\begin{tabular}{|c|c|c|c|c|c|c|}
\hline $\begin{array}{l}\text { Case } \\
\text { No. }\end{array}$ & Age, Sex & Presentation & Cyst Location & Cyst Type & $\begin{array}{l}\text { Follow-Up } \\
\text { (mos) }\end{array}$ & Outcomes \\
\hline 1 & 7 yrs, M & Headache, ADHD & Lt atrium & Arachnoid & 3 & $\begin{array}{l}\text { Persistent headaches, improve- } \\
\text { ment in ADHD; no ventricular } \\
\text { entrapment }\end{array}$ \\
\hline 2 & 4 mos, M & $\begin{array}{l}\text { Prenatal diagnosis, progres- } \\
\text { sive hydrocephalus }\end{array}$ & $\begin{array}{l}\text { Lt atrium \& oc- } \\
\quad \text { cipital horn }\end{array}$ & Ependymal/arachnoid & 66 & $\begin{array}{l}\text { Doing well; no hydrocephalus, no } \\
\text { ventricular entrapment }\end{array}$ \\
\hline 3 & 2 yrs, $M$ & $\begin{array}{l}\text { Incidental cyst w/ progres- } \\
\text { sive enlargement on serial } \\
\text { imaging }\end{array}$ & Lt atrium & Subependymal & 94 & $\begin{array}{l}\text { Doing well; no ventricular entrap- } \\
\text { ment }\end{array}$ \\
\hline 4 & $5 \mathrm{yrs}, \mathrm{F}$ & Headaches & Rt atrium & Arachnoid & 123 & $\begin{array}{l}\text { Improved headache control; no } \\
\text { ventricular entrapment }\end{array}$ \\
\hline 5 & 10 yrs, $F$ & Headache, bipolar disorder & Rt atrium & Arachnoid & 9 & $\begin{array}{l}\text { No headaches, improvement in } \\
\text { bipolar disorder; no ventricular } \\
\text { entrapment }\end{array}$ \\
\hline 6 & 4 yrs, M & $\begin{array}{l}\text { Headache, epilepsy, hemi- } \\
\text { paresis, ADHD, hydro- } \\
\text { cephalus }\end{array}$ & Lt atrium & Arachnoid & 2 & $\begin{array}{l}\text { Improved headache control, no sei- } \\
\text { zure recurrence, improvement in } \\
\text { ADHD; no ventricular entrapment }\end{array}$ \\
\hline 7 & 26 yrs, M & $\begin{array}{l}\text { Visual field defect, hemipa- } \\
\text { resis }\end{array}$ & Lt atrium & $\begin{array}{l}\text { Cystic anaplastic } \\
\text { astrocytoma }\end{array}$ & 24 & $\begin{array}{l}\text { Improved clinically; no ventricular } \\
\text { entrapment; died } 24 \text { mos after } \\
\text { surgery from tumor progression }\end{array}$ \\
\hline 8 & 35 yrs, M & Headache, HIV & $\begin{array}{l}\text { Atrium \& tem- } \\
\text { poral horn }\end{array}$ & Postinfectious & 12 & $\begin{array}{l}\text { Improved clinically; no ventricular } \\
\text { entrapment; died } 12 \text { mos after } \\
\text { surgery from non-CNS AIDS } \\
\text { complications }\end{array}$ \\
\hline 9 & 54 yrs, M & Hydrocephalus & Lt atrium & Postinfectious & 6 & $\begin{array}{l}\text { No ventricular entrapment; eventual } \\
\text { death due to CNS infection }\end{array}$ \\
\hline 10 & 5 mos, F & $\begin{array}{l}\text { Prenatal diagnosis, pro- } \\
\text { gressive temporal horn } \\
\text { entrapment }\end{array}$ & Rt atrium & Arachnoid & 11 & $\begin{array}{l}\text { Very well; reaching age-appropriate } \\
\text { milestones; no ventricular entrap- } \\
\text { ment }\end{array}$ \\
\hline 11 & 3 yrs, M & $\begin{array}{l}\text { Progressive temporal horn } \\
\text { entrapment }\end{array}$ & Rt atrium & Arachnoid & 39 & Very well; no ventricular entrapment \\
\hline 12 & $11 \mathrm{yrs}, \mathrm{F}$ & Hydrocephalus, headaches & Lt atrium & Arachnoid & 36 & $\begin{array}{l}\text { Persistent headaches; no ventricu- } \\
\text { lar entrapment }\end{array}$ \\
\hline 13 & $5 \mathrm{yrs}, \mathrm{M}$ & $\begin{array}{l}\text { ADHD, developmental delay, } \\
\text { bipolar disorder, head- } \\
\text { aches }\end{array}$ & Rt atrium & Arachnoid & 48 & $\begin{array}{l}\text { Persistent headaches, improvement } \\
\text { in behavior/psychiatric disorder; } \\
\text { no ventricular entrapment }\end{array}$ \\
\hline
\end{tabular}

terval resolution of ventricular entrapment coincided with improvement in behavior as documented in questionnaires reporting parents' perceptions before and after surgery. Furthermore, these perceptions were corroborated with reports from referring neurologists indicating a decrease in medication burden. While anecdotal in nature, these data suggest that at least some behavioral improvement may be attributed to cyst treatment.

From a technical standpoint, we believe that our approach, which initially places the endoscope posterior to the cyst, is ideal because it allows for access to all poles of the lateral ventricle enabling direct confirmation of ventricular communication. Conversely, an anterior approach would not be ideal for atrial lesions because access to all poles of the lateral ventricle would not be feasible. While shrinkage of the cyst from an anterior approach could reestablish CSF communication throughout the ventricular system in some cases, it would not be possible to confirm whether adherent membranes are present, causing persistent ventricular entrapment. This is particularly true in cystic tumors and in postinfectious multiloculated ventricles in which numerous membranes adhere to the ependymal surfaces.

Frameless stereotaxy is also an indispensable feature of the technique we present. The importance of bur-hole placement and trajectory planning cannot be overemphasized, as this will dictate whether the pathology can be easily reached and manipulated. Furthermore, the encysted ventricle is often quite distorted, and the usual anatomical landmarks become difficult to recognize. Neuronavigation provides data that the surgeon may use in addition to direct visualization to ensure safe exploration within the ventricles. ${ }^{11,24,26}$ As described, the use of a frameless stereotactic system with probes that fit within the working channel of the endoscope is ideal. This system allows tip tracking with the ability to guide the endoscope directly 

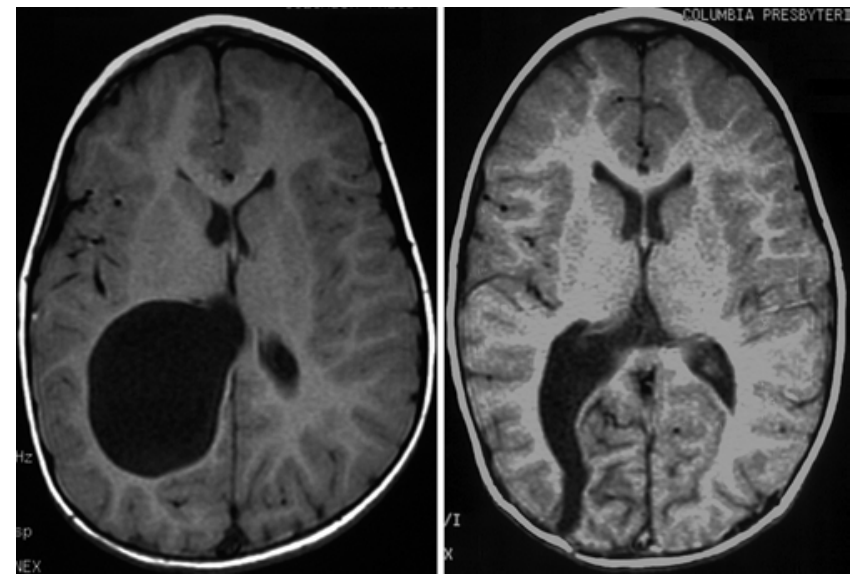

FIG. 4. Axial T1-weighted MR images demonstrate a large arachnoid cyst in the right atrium of the lateral ventricle creating mass effect on the surrounding structures (left). A significant reduction of mass effect is seen after transoccipital endoscopic surgery (right).

to a desired target without having to register it; thus, the cumbersome addition of a fiducial tree to the endoscope is eliminated. As previously reported, electromagnetic navigation systems provided an advantage because cranial fixation is obviated, allowing these techniques to be used in young children who cannot tolerate head pinning. ${ }^{13,15}$ Further advances in neuronavigation technology have allowed us to use pinless systems in optical navigation, where a fiducial reference frame is attached to the skull directly. We have used both electromagnetic and optical navigation systems with great ease in these and other endoscopic cases, as well as for placement of ventricular catheters when the anatomy is challenging.

It is notable that a wide septal fenestration may be performed using the operative approach we describe. Septal fenestration may be undertaken to create full communication within the ventricular system, facilitating placement of the simplest possible shunt system, preferably a single proximal catheter if concomitant communicating hydrocephalus is expected. As previously noted, excluding the 1 patient who was shunt dependent preoperatively, no patient in this study cohort required new permanent CSF diversion postoperatively. Thus, it was not necessary to routinely perform septal fenestrations in this patient cohort.

No direct comparison of endoscopic versus microsurgical or any other treatment strategy for atrial cysts has been performed. Although older reports indicate that atrial region cysts can be safely and effectively treated by microsurgical methods, ${ }^{18}$ more recent studies suggest that an endoscopic approach may, in fact, be advantageous. One study comparing 28 endoscopically treated to 39 nonendoscopically treated lateral ventricular cysts concluded that endoscopy may produce better clinical outcomes than nonendoscopic procedures. ${ }^{32}$ The authors found significantly less operative blood loss, less postoperative hydrocephalus, less cyst recurrence, and higher symptomatic improvement in the endoscopically treated group. Of note, the study included 4 endoscopically treated atrial cysts, but a detailed description of the operative approach was not included. In a contemporary review of the literature, open surgical treatment of intraventricular and paraventricular cysts was associated with reoperation rates of $7.4 \%$ to $12.4 \%$, and complication rates ranging from $8.3 \%$ to $28 \%$. Lower complication rates ranging from $1 \%$ to $5 \%$ was cited as the major advantage of endoscopic treatment. ${ }^{27}$ Our results are consistent with these data, as we have encountered no cyst recurrences or complications in any patient within this study at a mean of 36 months follow-up.

\section{Conclusions}

Stereotactic surgery utilizing an endoscopic transoccipital horn approach represents a safe and effective treatment strategy for patients with symptomatic atrial cysts of the lateral ventricle. Using this approach, all poles of the lateral ventricular system can be visualized and the unobstructed flow of CSF can be confirmed after cyst resection, obviating the need for additional diversion.

\section{References}

1. Backlund EO: Stereotactic catheter insertion: a new technique. Neurol Res 9:147-150, 1987

2. Bognar L, Markia B, Novak L: Retrospective analysis of 400 neuroendoscopic interventions: the Hungarian experience. Neurosurg Focus 19(6):E10, 2005

3. Boockvar JA, Shafa R, Forman MS, O'Rourke DM: Symptomatic lateral ventricular ependymal cysts: criteria for distinguishing these rare cysts from other symptomatic cysts of the ventricles: case report. Neurosurgery 46:1229-1233, 2000

4. Cappabianca P, Cinalli G, Gangemi M, Brunori A, Cavallo LM, de Divitiis E, et al: Application of neuroendoscopy to intraventricular lesions. Neurosurgery 62 (Suppl 2):575598,2008

5. Chamczuk AJ, Grand W: Endoscopic cauterization of a symptomatic choroid plexus cyst at the foramen of Monro: case report. Neurosurgery 66 (6 Suppl Operative):376-377, 2010

6. El-Ghandour NMF: Endoscopic cyst fenestration in the treatment of multiloculated hydrocephalus in children. J Neurosurg Pediatr 1:217-222, 2008

7. Emami-Naeini P, Nejat F, El Khashab M: Cystic choroid plexus papilloma with multiple mural nodules in an infant. Childs Nerv Syst 24:629-631, 2008

8. Gaab MR, Schroeder HW: Neuroendoscopic approach to intraventricular lesions. Neurosurg Focus 6(4):E5, 1999

9. Gangemi M, Maiuri F, Colella G, Sardo L: Endoscopic surgery for intracranial cerebrospinal fluid cyst malformations. Neurosurg Focus 6(4):E6, 1999

10. Greenfield JP, Souweidane MM: Endoscopic management of intracranial cysts. Neurosurg Focus 19(6):E7, 2005

11. Gumprecht H, Trost HA, Lumenta CB: Neuroendoscopy combined with frameless neuronavigation. Br J Neurosurg 14:129-131, 2000

12. Hervey-Jumper SL, Ziewacz JE, Heth JA, Sullivan SE: Frontal-to-temporal horn shunt as treatment for temporal horn entrapment. J Neurosurg 112:410-413, 2010

13. Karabatsou K, Hayhurst C, Buxton N, O’Brien DF, Mallucci CL: Endoscopic management of arachnoid cysts: an advancing technique. J Neurosurg 106 (6 Suppl):455-462, 2007

14. Kurokawa Y, Sohma T, Tsuchita H, Kitami K, Suzuki S, Ishikawa A: A case of intraventricular arachnoid cyst. How should it be treated? Childs Nerv Syst 6:365-367, 1990

15. Mangano FT, Limbrick DD Jr, Leonard JR, Park TS, Smyth MD: Simultaneous image-guided and endoscopic navigation 
without rigid cranial fixation: application in infants: technical case report. Neurosurgery $\mathbf{5 8}$ (4 Suppl 2):ONS-E377, 2006

16. Maurice-Williams RS, Choksey M: Entrapment of the temporal horn: a form of focal obstructive hydrocephalus. J Neurol Neurosurg Psychiatry 49:238-242, 1986

17. Nakase H, Hisanaga M, Hashimoto S, Imanishi M, Utsumi S: Intraventricular arachnoid cyst. Report of two cases. J Neurosurg 68:482-486, 1988

18. Nakase H, Ishida Y, Tada T, Sakaki T, Goda K, Tunoda S, et al: Neuroepithelial cyst of the lateral ventricle. Clinical features and treatment. Surg Neurol 37:94-100, 1992

19. Oertel JM, Wagner W, Mondorf Y, Baldauf J, Schroeder HW, Gaab MR: Endoscopic treatment of arachnoid cysts: a detailed account of surgical techniques and results. Neurosurgery 67:824-836, 2010

20. Okamura K, Watanabe M, Inoue N, Kanoh M, Ohno T, Mitsui Y, et al: [Intraventricular arachnoid cyst-on the origin of intraventricular arachnoid cysts.] No To Shinkei 48:10151021, 1996 (Jpn)

21. Pant B, Uozumi T, Hirohata T, Arita K, Kurisu K, Nakahara $\mathrm{T}$, et al: Endoscopic resection of intraventricular ependymal cyst presenting with psychosis. Surg Neurol 46:573-578, 1996

22. Pawar SJ, Sharma RR, Mahapatra AK, Dev EJ: Giant ependymal cyst of the temporal horn - an unusual presentation. Case report with review of the literature. Pediatr Neurosurg 34:306-310, 2001

23. Pradilla G, Jallo G: Arachnoid cysts: case series and review of the literature. Neurosurg Focus 22(2):E7, 2007

24. Rohde V, Reinges MH, Krombach GA, Gilsbach JM: The combined use of image-guided frameless stereotaxy and neuroendoscopy for the surgical management of occlusive hydrocephalus and intracranial cysts. Br J Neurosurg 12:531-538, 1998

25. Ross DA, Muraszko K, Dauser R: A special cyst puncture catheter for use in thick-walled or mobile intracranial cysts. Neurosurgery 34:191-192, 1994

26. Schulz M, Bohner G, Knaus H, Haberl H, Thomale UW: Navigated endoscopic surgery for multiloculated hydrocephalus in children. J Neurosurg Pediatr 5:434-442, 2010

27. Tamburrini G, D’Angelo L, Paternoster G, Massimi L, Caldarelli M, Di Rocco C: Endoscopic management of intra and paraventricular CSF cysts. Childs Nerv Syst 23:645651,2007
28. Tsugane R, Shimoda M, Yamaguchi T, Yamamoto I, Sato O: Entrapment of the temporal horn: a form of focal non-communicating hydrocephalus caused by intraventricular block of cerebrospinal fluid flow-report of two cases. Neurol Med Chir (Tokyo) 32:210-214, 1992

29. Watanabe T, Katayama Y: Evaluation by magnetic resonance imaging of the entrapped temporal horn syndrome. J Neurol Neurosurg Psychiatry 66:113, 1999

30. Xi-An Z, Songtao Q, Yuping P: Endoscopic treatment of intraventricular cerebrospinal fluid cysts: 10 consecutive cases. Minim Invasive Neurosurg 52:158-162, 2009

31. Yadav YR, Basoor A, Todorov M, Parihar V: Endoscopic management of large multicompartmental intraventricular arachnoid cyst extending from foramen magnum to foramen of Monro. Neurol India 58:481-484, 2010

32. Zhao P, Wang X, Li C, Gui S, Zong X, Zhang Y: The effectiveness of neuroendoscopic versus non-neuroendoscopic procedures in the treatment of lateral ventricular cysts: a retrospective medical record review study. BMC Neurol 13:59, 2013

\section{Author Contributions}

Conception and design: Ghatan. Acquisition of data: Ghatan, Ellis, McCormick. Analysis and interpretation of data: Ghatan, Ellis, McCormick. Drafting the article: Ghatan, Ellis. Critically revising the article: Ghatan, Ellis, Feldstein. Reviewed submitted version of manuscript: Ghatan, Ellis, Feldstein. Study supervision: Ghatan, Feldstein.

\section{Supplemental Information Videos}

Video 1, Media Player. http://mfile.akamai.com/21490/wmv/ digitalwbc.download.akamai.com/21492/wm.digitalsource-naregional/peds14-227_video_1.asx.

Video 1, Quicktime. http://mfile.akamai.com/21488/mov/ digitalwbc.download.akamai.com/21492/qt.digitalsource-global/ peds14-227_video_1.mov.

\section{Correspondence}

Saadi Ghatan, Department of Neurosurgery, 1000 10th Ave., Ste. 5G-80, New York, NY 10019. email: sghatan@chpnet.org. 